\title{
The state of evidence-based parenting interventions for parents who are substance-involved
}

\author{
Kimberly Renk' ${ }^{1}$ Neil W. Boris ${ }^{2}$, Ellen Kolomeyer ${ }^{1}$, Amanda Lowell ${ }^{1}$, Jayme Puff', Annelise Cunningham ${ }^{1}$, Maria Khan $^{1}$ and \\ Meagan McSwiggan'
}

Approximately 70 million children and adolescents live with at least one parent who abuses or is dependent on alcohol or an illicit substance. Given the negative parenting practices that substance-involved mothers and fathers tend to exhibit as well as the poor outcomes that their children, particularly their young children, experience, evidence-based parenting interventions are an important complement to substance abuse treatments. At this time, there are few studies that compare the efficacy of parenting interventions for these parents, however. Nonetheless, research has begun to examine skillbased and attachment-based parenting interventions for substance-involved families with young children. These parenting interventions should be considered within the context of the neurobiology of substance abuse, which emphasizes the role of dopamine in the reward systems that promote substance use. In the context of these neurobiological connections, parenting interventions that engender repeated intense emotional experiences may stimulate this same reward system and, therefore, may be more efficacious. Attachment-based interventions are particularly promising when such connections are considered. More attention needs to be paid to bringing impactful parenting interventions to substance-involved parents with young children.

A pproximately 70 million children and adolescents live with at least one parent who abuses or is dependent on alcohol or an illicit substance (1). Further, the National Council on Child Abuse and Family Violence (2) reported that substance misuse by parents was found in 40-80 percent of families who were identified for child welfare services. Amongst such families, parents' alcohol or drug use was the most common reason for children being removed from parents' care (3). Further, three of four child welfare service providers listed parents' substance abuse as the top reason for shifts in child maltreatment prevalence since the late 1980s (4). When such statistics are considered, it should be noted that the youngest children are over-represented (5), suggesting that families with young children would be in particular need of parenting interventions. When this information is coupled with the fact that parents' substance involvement is associated with many risks for children, risks complicated by harmful parenting practices (6), the need for parenting interventions for substance-involved families with young children is even more evident.

\section{NEUROBIOLOGY OF PARENTING AND SUBSTANCE USE}

When considering parenting behaviors exhibited in substanceinvolved families as well as reasons that certain parenting interventions may be more efficacious than others, new findings in neurobiology may provide useful clues for researchers and health service providers. In particular, dopamine is a neurotransmitter involved in reward and motivation pathways and is central to substance abuse. Coincidentally, dopamine also is released during pleasing parent-child interactions. In other words, substance abuse impacts the dopaminergic system, the same system that is critical for parents' capacity to invest in their children (7). Thus far, animal studies supported a connection between substance abuse and bonding. For example, a study examining amphetamine abuse in female prairie voles suggested that their amphetamine abuse impaired pair bonding and partner preferences through oxytocin-mediated mechanisms and that oxytocin and dopamine systems in brain circuitry mediated the relationship between substance abuse and pair bonding (8). Although these findings provide insight into possible mechanisms, the bigger question is how these systems might be important to parent-young child bonding.

Whether certain parenting interventions can stimulate dopaminergic and related systems needs to be tested directly. Nonetheless, the possible importance of these systems for the application and efficacy of parenting interventions was raised recently $(9,10)$. Certainly, models of mammalian behavior suggested that dopamine, along with other biological mechanisms, activates the neural pathways necessary for parents' motivation to bond with, nurture, and protect offspring, with these parenting behaviors shaping offspring neural and social development (11). Given these mammalian models, it may be that craving substances competes with and impedes substance-involved parents' capacity for positive caregiving (12). Further, repeated exposure to addictive substances likely reduces parents' dopaminergic response to stress, resulting in

'Department of Psychology, Clinical Psychology Ph.D. Program, University of Central Florida, Orlando, Florida; ${ }^{2}$ Division of Behavioral Health, Department of Pediatrics, Nemours Children's Hospital and University of Central Florida College of Medicine, Orlando, Florida. Correspondence: Kimberly Renk (Kimberly.Renk@ucf.edu)

Received 15 April 2015; accepted 14 September 2015; advance online publication 11 November 2015. doi:10.1038/pr.2015.201 
vulnerability to negative emotions and extreme distress when caring for distressed children. Such experiences can trigger relapses for parents who are substance-involved (13). Given the powerful nature of the dopaminergic system, interventions meant to change parenting behaviors in substance-involved families will need to be particularly potent. A brief summary of the problematic parenting that can be seen in substanceinvolved families as well as a selective comparative review of skill-based and attachment-based parenting interventions relevant to these families follows.

\section{PROBLEMATIC PARENTING WITH SUBSTANCE INVOLVEMENT}

Consistent with the animal models and dysregulation of the dopaminergic system described above, parents who are substance-involved have high rates of psychopathology overall (14). The picture for these parents is complex, however, as childhood maltreatment and trauma also are common, particularly for those parents who are involved with child welfare systems (15) and/or who have been incarcerated (e.g., (16,17)). In other words, childhood maltreatment experiences are related closely to substance misuse in adulthood (e.g., (18)). In turn, the presence of childhood maltreatment, trauma, and psychopathology coupled with substance misuse is associated with parenting deficits (19). Research further suggested that parents who are substance-involved exhibit different parenting behaviors than those who are not substance-involved, with such differences varying with the characteristics of parents' current drug use (see (20) and (21) for reviews). For example, parents who are substance-involved are more likely to exhibit greater parenting stress (22), decreased attentiveness and engagement with their children (23), more authoritarian parenting (24), and dysfunctional or harsh disciplinary practices (25). Given such parenting practices, it should not be a surprise that children of these parents are three times more likely to be abused and four times more likely to be neglected relative to children of parents who are not substance-involved (26). Such statistics also would be consistent with the notion of intergenerational abuse and neglect experiences, with those who experienced childhood maltreatment being more likely to have a child referred to child protection services (e.g., $(27,28)$ ).

Given these findings, children of parents who are substanceinvolved are more likely to have adverse cognitive, physical, emotional, behavioral, and social outcomes. For example, although it can be difficult to tease apart the direct impact of in utero substance exposure from shared genetic effects that are themselves associated with impairments in social behavior and emotion regulation, children of parents who are substance-involved often face multiple developmental insults (see (29) and (30) for reviews). Clearly, the youngest children are most vulnerable to the effects of these poor parenting practices (5), thereby requiring the most immediate intervention. Unfortunately, substance abuse treatment for parents is limited in accessibility (29) and focuses almost exclusively on parents' substance misuse, rather than on improving parent-child interactions and/or child adjustment (12). Even when parents who are substance-involved also are receiving child welfare services, there is evidence that the quality and intensity of parenting education programs are variable. Further, many of the existing efficacy studies are of low quality (31).

Consequently, parenting interventions that can be delivered while parents also address their substance misuse demand to be investigated. In a recent review on parenting interventions that were integrated into substance abuse treatment programs, Kerwin (21) suggested that there were variable outcomes when using integrated approaches and that more research was needed. Clearly, understanding the factors that could foster optimal outcomes for integrated interventions for parents' substance misuse and their parenting is complex (21), particularly when statistics suggested that $60-75 \%$ of mothers who entered drug treatment left before their treatment was completed (32). With relevance to the current review, however, Niccols et al. (33) noted that parenting interventions focusing on parentchild attachment may be more effective than those focusing on skill development when it comes to fostering parenting improvements for parents who are substance-involved.

Certainly, the complex histories of parents who are substance-involved (e.g., including the chaotic lifestyle that generally co-occurs with substance misuse), the problematic parenting that is exhibited by these parents, and the difficulties in delivering integrated interventions for these parents (e.g., including these parents' variable outcomes and high rates of attrition from interventions) are inherent barriers to providing parenting interventions. In an effort to combat these barriers, there is an emerging consensus that parenting interventions should involve significant community advocacy (34) and should be integrated into programs that already serve substance-involved individuals of childbearing age (33). For example, more research on interventions that can be embedded into residential treatment programs, jails, and prisons is needed. A call for such research seems commonsensical when it is noted that most incarcerated women are parents, with over one-third of these mothers having more than one child (35). Consequently, parents who are incarcerated will need programs with multiple components that can be combined with longer term supports so that they can succeed and foster more positive outcomes for their young children. Nonetheless, a sample of parenting interventions that are available currently are discussed in the following sections, with two types of interventions (i.e., skill-based and attachment-based) being considered.

\section{SKILL-BASED PARENTING INTERVENTIONS}

Skill-based parenting interventions mainly have been examined with somewhat older children (relative to those that are the focus of this review) and typically involve cognitive-behavioral components (which have received support in many examinations of evidence-based interventions; (36)). In skill-based parenting interventions, parents are asked to explore their thinking about parenting approaches while also being taught how to change their parenting behaviors. A multitude of different skill-based parenting interventions have been developed 
and examined for effectiveness (e.g., Incredible Years, (37); Parent-Child Interaction Therapy, (38); Parent Management Training, (39); Triple P Positive Parenting Program, (40)). Relatively few skill-based parenting intervention programs have been deemed efficacious for parents who are substanceinvolved, particularly for those parents who have young children, however.

Nonetheless, to provide a context for interventions that may be helpful, a few examples of interventions that have been examined in families with somewhat older children will be examined first. One intervention, the Strengthening Families Program (SFP; (41)), was examined with diverse parents who were substance-involved in randomized control trials by the National Institute of Drug Abuse $(42,43)$. Key concepts in the SFP include having parents use praise, ignoring, clear communication of expectations, problem solving, and cognitive restructuring of thoughts and reduce coercive parent-child interactions by discussing family violence and abuse (43). This cost effective intervention was adapted culturally to increase its engagement and acceptability $(44,45)$ and can be delivered in individual or group format with two levels of potency (i.e., high-risk families may participate in 14 weekly sessions, whereas lower-risk families may participate in seven weekly sessions). After being utilized with over 1,600 families, research suggested that the SFP increases positive parenting behaviors (e.g., involvement), family functioning (e.g., communication), and parental efficacy and decreases parents' substance use and depression, corporal punishment, and children's behavior problems $(43,46)$. The largest effect sizes $(d=0.77)$ were found for families with children who were 6-11 y of age (43), although future work should examine the appropriateness of this intervention with families of younger children. Overall, though, in a sample of parents who were substance-involved and receiving child welfare services, $47 \%$ of these parents achieved reunification with their children (47).

With regard to integrating skill-based parenting interventions into settings already serving parents who are substance-involved, the Parenting While Incarcerated (PWI; (48)) curriculum was adapted from the SFP (49). As part of this curriculum, the SFP lesson on substance abuse and families was expanded to include the effects of addiction on prison sentences and information on how parents can help prevent substance abuse in their own children to better meet the needs of incarcerated women. This program also stresses the importance of communication and maintenance of a coparenting relationship between incarcerated mothers and their children's current caregiver. This communication and cooperation provides continuity for children and is helpful when these mothers complete their prison time (50).

Beyond these interventions, Kumpfer, Alvarado, Tait, and Turner (51) assessed the effectiveness of a multicomponent prevention program called Project SAFE (Strengthening America's Families and Environment) in a sample of 655 First Graders from 12 rural schools. This study randomly assigned these First Graders to either the I Can Problem Solve (ICPS) program (i.e., a child intervention designed to enhance problem solving and critical thinking skills in school; (52)) alone or with the SFP or to SFP only. Results suggested that Project SAFE was more effective than either ICPS or SFP alone, resulting in significant improvement in factors that can affect substance abuse risk (e.g., family relationships, behavioral regulation, parenting skills, social competence, and school bonding).

For parenting interventions meant to address the needs of substance-involved parents who have young children, fewer examples are available. For example, Huebner (53) assessed the effectiveness of a health-clinic-based parenting intervention for 199 parents who were high-risk (including being substanceinvolved) and who had young children ranging in age from birth to $3 \mathrm{y}$. This program was meant to decrease insensitive and inconsistent parenting and to provide anticipatory guidance, support, and skills training as a preventive intervention. From baseline to postintervention, participating parents demonstrated decreases in parenting stress, increases in ratings of infants' environments promoting favorable development, and increases in positive parent-infant interaction characteristics (53). A paraprofessional advocacy parenting intervention for 51 mothers who were substance-involved also was examined by Grant et al. (54). This intervention consisted of establishing a therapeutic relationship, identifying goals for the mothers, establishing service provider linkages toward a team approach, using written agreements, role modeling and teaching basic life skills, and evaluation. These women demonstrated decreased substance use as well as increased involvement with substance treatment, use of birth control, and involvement with skillbuilding services (e.g., parenting classes; (54)).

Skill-based interventions meant to target parents of young children also have been integrated into school settings. For example, Field et al. (55) integrated a multicomponent intervention designed for parents of young children into afternoon programming at a vocational high school for 126 young mothers, some of whom were substance-involved, while their infants were provided daycare. This intervention included an outpatient drug rehabilitation curriculum, educational/vocational counseling, daily living/social rehabilitation, relaxation therapy, and parenting classes (e.g., regarding developmental milestones and child-rearing practices). Although infants of mothers who were substance-involved did more poorly on many measures on the Brazelton Neonatal Behavioral Assessment Scale and these mother-infant dyads evidenced more problematic interactions at baseline relative to infants of mothers who were not substance-involved, these groups demonstrated similar functioning at 3- and 6-mo assessments, and infants of mothers who were substance-involved exceeded infants of mothers who were not substance-involved on scores of early social communication, the Bayley Mental scale, head circumference, and lack of pediatric complications at a 12-mo assessment (55).

Home visiting interventions also have provided a mechanism for reaching substance-involved parents who have young children. For example, Black et al. (56) examined a biweekly home visiting intervention designed to provide maternal support and promote parenting, child development, the use of 
resources, and advocacy for mothers who were substanceinvolved. Mothers in this intervention began receiving visits prior to delivery and continued receiving visits until infants were 18 mo of age. When infants were 6 mo of age, infants of mothers in the intervention group had marginally higher cognitive scores. Further, when infants were 18 mo of age, the 30 mothers in the intervention group were marginally less likely to be using substances, were more emotionally responsive, and provided marginally more stimulation than the 29 mothers in the control group (on average). Overall, intervention mothers endorsed more normative parenting attitudes and more childrelated stress when infants were 18 mo of age relative to baseline (56). Similarly, Schuler et al. (57) examined a weekly home visiting intervention that was designed to increase maternal empowerment and promote child development. Mothers who were substance-involved received weekly visits from 6 wk postpartum until 6 mo postpartum and then biweekly visits until 18 mo postpartum. Although this intervention showed no measured effect when 67 intervention mothers were compared to 64 control mothers, mothers who remained substanceinvolved showed lower competence, with lower competence being associated with poorer parenting attitudes during mother-child interactions (57).

Although the majority of these studies suggested that skillbased parenting interventions can be useful in addressing the parenting of mothers and fathers who are substance-involved and in achieving better outcomes for young children, it is noteworthy that most of these parenting interventions tend to be used more readily once children have entered school, perhaps because many of the featured skills are more applicable to children who are school age (although some have relevance for young children as well). Further, these parenting interventions apply principles of human learning to the amelioration of child behavior problems by changing parents' behavior (39) and by altering external contingencies for behavior via parents (58). Although skill-based parenting interventions show promise, they also have been criticized for not attending to the emotional quality of parent-child relationships (59). Overall, more research is needed regarding the use of skill-based parenting interventions when parents are substance-involved and have young children.

\section{ATTACHMENT-BASED PARENTING INTERVENTIONS}

In contrast to skill-based parenting interventions, attachmentbased parenting interventions foster the psychobiological process of attachment between parents and their children so that lasting emotional connections can be built. Supporting or restoring such connections can be critical for high-risk parents, such as parents who are substance-involved. Further, although skill-based parenting interventions focus on thoughts and behavior, attachment-based parenting interventions focus on having parents reflect on their children's attachment needs in an effort to foster longstanding changes in their parenting interactions. Consistent with the neurobiology of parenting, these interactive mental states of parents and their children emphasize interpersonal neurobiology, promoting the potential for lasting impacts on functioning (60). These targets allow for the use of attachment-based parenting interventions with the parents of even very young children, including infants.

Key to these interventions is the concept of reflective functioning (i.e., individuals' ability to organize their experience of themselves and others in the context of mental states). For example, when mothers identify their young children's emotions, relate these emotions to prior experiences, and then provide an appropriate emotional response, these children learn how to interpret and respond to others (61). Further, attachment refers to the emotional bond that develops between young children and their parents as parents care for and interact with their young children. This emotional bond allows young children to maintain proximity to their parent(s) to ensure their survival, allows individuals to cope with their world (62), and promotes the development of emotional regulation (63) and an understanding of how relationships work (via internal working models; $(64,65))$. These issues are particularly relevant to parents who are substance-involved, as both substanceinvolved individuals (66) and children of parents who are substance-involved (67) tend to exhibit less secure attachment. Consistently, such interventions address parent-infant attachment and parents' own history of problematic attachment and trauma (i.e., both issues that frequently are identified as problematic for substance-involved parents; (68)).

In fact, several attachment-based interventions have been used with parents who are substance-involved. First, the Mothers and Toddlers program (MTP; (12)) is a 12-session parenting intervention founded on "psychosocial and neurobiological mechanisms of attachment and addiction" (p. 502). This program can serve as an adjunct to individual substance abuse treatment and was developed to improve caregiving behavior by intervening at the level of maternal reflective functioning and representation quality (69). Within regard to reflective functioning, this intervention addresses mothers' ability to identify and downregulate their own distressing emotions as well as their ability to recognize and empathize with their children's emotions and needs $(13,70)$. In a pilot study examining MTP in a small sample of 14 substance-involved mothers of toddlers who ranged in age from 12 to 36 mo, preliminary pre-postcomparisons indicated that MTP was effective in increasing mothers' reflective functioning, sensitivity to child cues, and responses to child distress (12). These mechanisms of change also improved mothers' depressive symptoms, abstinence from drugs, and responsive caregiving to their children's cues as well as their children's clarity of cues immediately posttreatment and at 6-wk follow-up in a sample of 47 substanceinvolved mothers of young children (i.e., ranging in age from birth to $36 \mathrm{mo}$ ) who were randomized to MTP or a parent education program $(13,70)$.

Second, Attachment and Biobehavioral Catchup ( $A B C$; (71)) is a home-based 10 -session intensive parenting intervention designed to enhance nurturance and increase synchronous interactions between high-risk caregivers and their infants (72). Each session involves both the parent and his or her child, includes a videotaped dyadic interaction, and 
a review of this video footage. With regard to efficacy for parents who are substance-involved (73), pilot data collected from 21 predominantly Caucasian mothers and their infants in a residential substance abuse treatment program suggested that these mothers had more sensitive and supportive parenting behaviors following random assignment to $\mathrm{ABC}$ relative to a control group (74).

Next, the Circle of Security Parenting Intervention (CoS; (75)) has two different group formats: a 20-wk individualized program and a condensed 8-wk digital video disk-based program. CoS improves the parent-young child relationship by enhancing parents' understanding of their young children's cues, observation and inference, emotion regulation, responsiveness, and reflective functioning. CoS also was used in alternate settings where parents who were substance-involved already were being served. Pilot data on the 20 -wk CoS program collected from 20 mothers and their infants who were participating in Tamar's Children program, a 15-mo jail diversion residential program for pregnant nonviolent women who were substance-involved, suggested that these mothers demonstrated higher levels of sensitivity and had infants who exhibited more secure attachment post-treatment (76). At this time, researchers also are examining the feasibility of the 8-wk digital video disk-based program for mothers in residential drug treatment facilities $(77,78)$, with initial studies suggesting that this program can promote improved parenting locus of control (78), parenting attributions, discipline practices (77), and emotion regulation $(77,78)$.

Further, Minding the Baby (MTB; (79)) is a home visiting intervention for high-risk parents that is implemented by an interdisciplinary team that teaches parents to be mindful of their children's emotional needs. Mentalization (i.e., individuals' ability to envision their own mental states and those of others and to predict behavior based on these mental states) and reflective functioning are key components. Although this intervention has not been validated specifically for parents who are substance-involved, its theoretical framework was proposed as an effective means of treating problematic parent-young child relationships with these parents (80). Finally, Cherish the Family (CTF; (76)) is an intervention developed specifically for use with parents who are substance-involved and who are at risk of abandoning their children or of having their parental rights terminated. Services are intended for use during reintegration or reunification following parents' substance involvement. This individualized multifaceted intervention addresses parent-young child bonding as well as parents' maximization of community support, stress management, and physical health. Practitioners provide attachment-based skills to parents in addition to court support, liaison services, parent support groups, and emotional support. Initial results did not provide information regarding attachment or psychological outcomes for parents or their young children; however, 45 parents of young children who ranged in age from 0 to $3 \mathrm{y}$ demonstrated enhanced engagement with community resources, improved family interactions and parenting capabilities, and less ambivalence regarding reunification with their children (81).

\section{CONCLUSIONS}

With approximately 70 million children and adolescents living with at least one parent who abuses or is dependent on alcohol or an illicit substance (1), health service providers should become aware of the evidence-based parenting interventions that are available. Traditional substance abuse treatments focus almost exclusively on parents' substance use, rather than on improving parent-young child interactions and/or young child adjustment (12). Evidence-based parenting interventions are a critical adjunctive treatment given that the young children of parents who are substance-involved are at such high risk for a variety of adverse outcomes. Although there is not enough comparative data to suggest which type of parenting intervention should be used for any given parent who is substance-involved, data on attachment-based parenting interventions are growing. Whether attachment-based parenting interventions can tap into the dopaminergic pathways linked to both substance involvement and parents' capacity to invest in their children and adolescents is an intriguing question (7). In fact, using new research on the neurobiology of parenting to inform future work in evidence-based parenting interventions, particularly for parents who are substance-involved and their young children, may allow future interventions to become more potent.

\section{STATEMENT OF FINANCIAL SUPPORT}

No financial support was received to support this manuscript.

Disclosure: None of the authors has financial ties or potential/perceived conflicts of interest related to the content of this manuscript.

\section{REFERENCES}

1. Substance Abuse and Mental Health Services Administration (SAMHSA), Office of Applied Studies. The NSDUH Report: Children Living With Substance-Dependent or Substance-Abuse Parents: 2002 to 2007. Rockville, MD: Substance Abuse and Mental Health Services Administration, 2009.

2. National Council on Child Abuse and Family Violence. Parental substance abuse a major factor in child abuse and neglect, 2015. http://www.nccafv. org/parentalsubstanceabuse.htm.

3. Child Welfare Information Gateway. Parental substance abuse as a risk factor for maltreatment and child welfare, 2014. https://www.childwelfare. gov/pubPDFs/parentalsubabuse.pdf.

4. National Association for Children of Alcoholics. Children of addicted parents: Important facts, 2015. http://www.nacoa.net/pdfs/addicted.pdf.

5. Osofsky JD, Lieberman AF. A call for integrating a mental health perspective into systems of care for abused and neglected infants and young children. Am Psychol 2011;66:120-8.

6. Kroll B. Living with an elephant: Growing up with parental substance misuse. Child Fam Social Work 2004;9:129-40.

7. Edelman GM, Tononi G. Neural Darwinism: The brain as a selectional system. In: Cornwell J, ed. Nature's Imagination: The Frontiers of Scientific Vision. New York: Oxford University Press, 1995:78-100.

8. Young KA, Liu Y, Gobrogge KL, Wang H, Wang Z. Oxytocin reverses amphetamine-induced deficits in social bonding: evidence for an interaction with nucleus accumbens dopamine. J Neurosci 2014;34:8499-506.

9. Mayes L, Rutherford H, Suchman N, Close N. The neural and psychological dynamics of adults' transition to parenthood. Zero Three 2012;33: 83-4.

10. Pajulo M, Suchman N, Kalland M, Sinkkonen J, Helenius H, Mayes L. Role of maternal reflective ability for substance abusing mothers. J Prenat Perinat Psychol Health 2008;23:13-31.

11. Rilling JK, Young LJ. The biology of mammalian parenting and its effect on offspring social development. Science 2014;345:771-6. 
12. Suchman N, Decoste C, Castiglioni N, Legow N, Mayes L. The mothers and toddlers program: preliminary findings from an attachment-based parenting intervention for substance-abusing mothers. Psychoanal Psychol 2008;25:499-517.

13. Suchman NE, Decoste C, McMahon TJ, Rounsaville B, Mayes L. The mothers and toddlers program, an attachment-based parenting intervention for substance-using women: results at 6-week follow-up in a randomized clinical pilot. Infant Ment Health J 2011;32:427-49.

14. Swendsen JD, Merikangas KR. The comorbidity of depression and substance use disorders. Clin Psychol Rev 2000;20:173-89.

15. Kang S, Magura S, Laudet A, Whitney S. Adverse effect of child abuse victimization among substance-using women in treatment. J Interpers Violence 1999;14:657-70.

16. Asberg K, Renk K. Substance use coping as a mediator of the relationship between trauma symptoms and substance use consequences among incarcerated females with childhood sexual abuse histories. Subst Use Misuse 2012;47:799-808.

17. Asberg K, Renk K. Comparing incarcerated and college student women with a history of childhood sexual abuse: The role of abuse severity, support, and substance abuse. Psychol Trauma: Theory Research Practice Policy 2013;5:167-75.

18. Kunitz SJ, Levy JE, McCloskey J, Gabriel KR. Alcohol dependence and domestic violence as sequelae of abuse and conduct disorder in childhood. Child Abuse Negl 1998;22:1079-91.

19. Cohen LR, Hien DA, Batchelder S. The impact of cumulative maternal trauma and diagnosis on parenting behavior. Child Maltreat 2008;13:27-38.

20. Johnson MO. Mother-infant interaction and maternal substance use/abuse: An integrative review of research literature in the 1990s, 2001. http://www. stti.iupui.edu/cgi-bin/ msmgo.exe?grab_id=253\&extra_arg=\&cfgname= mssfindpreview\%2ecfg\&host_id=42 \&page_id=16121856\&query=mothe rinfant+relations

21. Kerwin ME. Collaboration between child welfare and substance-abuse fields: combined treatment programs for mothers. J Pediatr Psychol 2005;30:581-97.

22. Nair P, Schuler ME, Black MM, Kettinger L, Harrington D. Cumulative environmental risk in substance abusing women: early intervention, parenting stress, child abuse potential and child development. Child Abuse Negl 2003;27:997-1017.

23. Mayes LC, Feldman R, Granger RH, Haynes OM, Bornstein MH, Schottenfeld R. The effects of polydrug use with and without cocaine on motherinfant interaction at 3 and 6 months. Infant Behav Dev 1997;20:489-502.

24. Wellisch DK, Steinberg MR. Parenting attitudes of addict mothers. Int J Addict 1980;15:809-19.

25. Fals-Stewart W, Kelley ML, Fincham FD, Golden J, Logsdon T. Emotional and behavioral problems of children living with drug-abusing fathers: comparisons with children living with alcohol-abusing and non-substance-abusing fathers. J Fam Psychol 2004;18:319-30.

26. Kelleher K, Chaffin M, Hollenberg J, Fischer E. Alcohol and drug disorders among physically abusive and neglectful parents in a community-based sample. Am J Public Health 1994;84:1586-90.

27. Dixon L, Browne K, Hamilton-Giachritsis C. Risk factors of parents abused as children: a mediational analysis of the intergenerational continuity of child maltreatment (Part I). J Child Psychol Psychiatry 2005;46:47-57.

28. Pears KC, Capaldi DM. Intergenerational transmission of abuse: a twogenerational prospective study of an at-risk sample. Child Abuse Negl 2001;25:1439-61.

29. Boris NW. Parental substance abuse. In: Zeanah CJ, ed. Handbook of Infant Mental Health. 3rd edn. New York: The Guilford Press, 2009:171-9.

30. Richter L, Richter DM. Exposure to parental tobacco and alcohol use: effects on children's health and development. Am J Orthopsychiatry 2001;71:182-203.

31. Johnson M, Stone S, Lou C, Ling J, Claassen J, Austin MJ. Assessing parent education programs for families involved with child welfare services: evidence and implications. J Evid Based Soc Work 2008;5:191-236.

32. Comfort M, Sockloff A, Loverro J, Kaltenbach K. Multiple predictors of substance-abusing women's treatment and life outcomes: a prospective longitudinal study. Addict Behav 2003;28:199-224.
33. Niccols A, Milligan K, Sword W, Thabane L, Henderson J, Smith A. Integrated programs for mothers with substance abuse issues: A systematic review of studies reporting on parenting outcomes. Harm Reduct J 2012;9:14.

34. Grant TM, Ernst CC, Streissguth AP. An intervention with high-risk mothers who abuse alcohol and drugs: the Seattle Advocacy Model. Am J Public Health 1996;86:1816-7.

35. Glaze LE, Maruschak LM. Parents in prison and their minor children. Bureau Justice Statistics Special Report, 2008. http://www.bjs.gov/content/ pub/pdf/pptmc.pdf.

36. Barth RP, Landsverk J, Chamberlain P, et al. Parent-training programs in child welfare services: Planning for a more evidence-based approach to serving biological parents. Res Soc Work Prac 2005;15:353-71.

37. Webster-Stratton C. The Incredible Years: A Trouble-Shooting Guide for Parents of Children Aged 2-8 Years. Toronto, Ontario: Umbrella Press, 1992.

38. Hembree-Kigin TL, McNeil CB. Parent-Child Interaction Therapy. New York: Plenum Press, 1995.

39. Kazdin AE. Parenting Management Training. New York: Oxford University Press, 2005.

40. Sanders MR. Triple P-Positive Parenting Program: towards an empirically validated multilevel parenting and family support strategy for the prevention of behavior and emotional problems in children. Clin Child Fam Psychol Rev 1999;2:71-90.

41. Alvarado R, Kumpfer KL. Strengthening America's families. Juvenile Justice 2000;7:8-18.

42. Kumpfer KL. Selective preventive interventions: The strengthening families program. In: Ashery RS, Robertson EB, Kumpfer KL. Drug Abuse Prevention Through Family Interventions. Rockville: National Institute on Drug Abuse, 1998

43. Kumpfer KL, Whiteside HO, Greene JA, Allen KC. Effectiveness outcomes of four age versions of the Strengthening Families Program in statewide field sites. Group Dyn: Theor Res Pract 2010;14:211-29.

44. Hurwich-Reiss E, Rindlaub LA, Wadsworth ME, Markman HJ. Cultural adaptation of a family strengthening intervention for low-income Spanishspeaking families. J Lat Psychol 2014;2:21-36.

45. Johnson-Motoyama M, Brook J, Yan Y, McDonald TP. (2013). Cost analysis of the strengthening families program in reducing time to family reunification among substance-affected families. Child Youth Serv Rev 2013;35:244-52.

46. Kumpfer KL. Strengthening America's Families: Exemplary Parenting and Family Strategies for Delinquency Prevention. Washington D.C.: Office of Juvenile Justice and Delinquency Prevention, Office of Justice Programs, US Department of Justice, 1999.

47. Brook J, McDonald TP, Yan Y. An analysis of the impact of the Strengthening Families Program on family reunification in child welfare. Child Youth Serv Rev 2012;34:691-5.

48. Miller AL, Weston LE, Perryman J, Horwitz T, Franzen S, Cochran, S. Parenting while incarcerated: Tailoring the Strengthening Families Program for use with jailed mothers. Child Youth Serv Rev 2014;44:163-70.

49. Kumpfer K, DeMarsh J, Child W. Strengthening Families Program: Children's Skills Training Curriculum Manual, Parent Training Manual, Children's Skill Training Manual, and Family Skills Training Manual. Salt Lake City: Social Research Institute, Graduate School of Social Work, University of Utah, 1989.

50. Cecil DK, McHale J, Strozier A, Pietsch J. Female inmates, family caregivers, and young children's adjustment: A research agenda and implications for corrections programming. J Crim Justice 2008;36:513-21.

51. Kumpfer KL, Alvarado R, Tait C, Turner C. Effectiveness of schoolbased family and children's skills training for substance abuse prevention among 6-8-year-old rural children. Psychol Addict Behav 2002;16(4 Suppl):S65-71.

52. Shure MB, Spivack G. Interpersonal cognitive problem solving and primary prevention: Programming for preschool and kindergarten children. J Clin Child Psychol 1979;8:89-94.

53. Huebner CE. Evaluation of a clinic-based parent education program to reduce the risk of infant and toddler maltreatment. Public Health Nurs 2002;19:377-89. 
54. Grant TM, Ernst CC, Streissguth AP, Phipps P, Gendler B. When case management isn't enough: a model of paraprofessional advocacy for drug- and alcohol-abusing mothers. J Case Manag 1996;5:3-11.

55. Field TM, Scafidi F, Pickens J, et al. Polydrug-using adolescent mothers and their infants receiving early intervention. Adolescence 1998;33:117-43.

56. Black MM, Nair P, Kight C, Wachtel R, Roby P, Schuler M. Parenting and early development among children of drug-abusing women: effects of home intervention. Pediatrics 1994;94(4 Pt 1):440-8.

57. Schuler ME, Nair P, Black MM. Ongoing maternal drug use, parenting attitudes, and a home intervention: effects on mother-child interaction at 18 months. J Dev Behav Pediatr 2002;23:87-94.

58. Coyne J. Parenting from the outside-in: Reflections on parent training during a potential paradigm shift. Australian Psychol 2013;48:379-87.

59. Suchman N, Mayes L, Conti J, Slade A, Rounsaville B. Rethinking parenting interventions for drug-dependent mothers: from behavior management to fostering emotional bonds. J Subst Abuse Treat 2004; 27:179-85.

60. Siegel D. Healing Trauma: Attachment, Mind, Body, and Brain. New York: W. W. Norton, 2003.

61. Fonagy P, Target M, Steele H, Steele M. Reflective-Functioning Manual, Version 5.0, For Application to Adult Attachment Interviews. London: University College London, 1998.

62. Bowlby J. Attachment and Loss, Volume 1: Attachment. New York: Basic Books, 1969.

63. Bowlby J. Attachment and Loss, Volume 2: Separation. New York: Basic Books, 1973

64. Bowlby J. A Secure Base. New York: Basic Books, 1988.

65. Stern D. The Interpersonal World of the Infant. New York: Basic Books, 1985.

66. Thorberg FA, Lyvers M. Attachment in relation to affect regulation and interpersonal functioning among substance use disorder in patients. Addict Res Theor 2010;18:464-78.

67. Hoppe MJ, Wells EA, Haggerty KP, Simpson EE, Gainey RR, Catalano RF. Bonding in a high-risk and a general sample of children: Comparison of measures of attachment and their relationship to smoking and drinking. J Youth Adolesc 1998;27:59-81.

68. Berlin LJ, Zeanah CH, Lieberman AF. Prevention and intervention programs for supporting early attachment security. In: Cassidy J, Shaver PR, eds. Handbook of Attachment: Theory, Research, and Clinical Applications. 2nd edn. New York: Guilford Press, 2008:745-61.

69. Suchman NE, Decoste C, Rosenberger P, McMahon TJ. Attachmentbased intervention for substance-using mothers: a preliminary test of the proposed mechanisms of change. Infant Ment Health J 2012;33: $360-71$.
70. Suchman NE, DeCoste C, Castiglioni N, McMahon TJ, Rounsaville B, Mayes L. The Mothers and Toddlers Program, an attachment-based parenting intervention for substance using women: post-treatment results from a randomized clinical pilot. Attach Hum Dev 2010;12:483-504.

71. Bick J, Bernard K, Dozier M. Attachment and biobehavioral catch-up: An attachment-based intervention for substance using mothers and their infants. In: Suchman NE, Pajulo M, Mayes LC, eds. Parenting and Substance Abuse: Developmental Approaches to Intervention. New York: Oxford University Press, 2013:303-20.

72. Bernard K, Meade EB, Dozier M. Parental synchrony and nurturance as targets in an attachment based intervention: building upon Mary Ainsworth's insights about mother-infant interaction. Attach Hum Dev 2013;15:507-23.

73. Dozier M, Bernard K, Bick J. Attachment-based intervention for substance using mothers of infants. In: Suchman NE, Pajulo M, Mayes LC, eds. Parenting and Substance Addiction: Developmental Approaches to Intervention. New York: Oxford University Press, 2013:303-20.

74. Berlin LJ, Shanahan M, Appleyard Carmody K. Promoting supportive parenting in new mothers with substance-use problems: a pilot randomized trial of residential treatment plus an attachment-based parenting program. Infant Ment Health J 2014;35:81-5.

75. Powell B, Cooper G, Hoffman K, Marvin B. The Circle of Security Intervention: Enhancing Attachment in Early Parent-Child Relationships. New York: Guilford Press, 2014.

76. Cassidy J, Ziv Y, Stupica B, et al. Enhancing attachment security in the infants of women in a jail-diversion program. Attach Hum Dev 2010;12:333-53.

77. Horton E, Murray C. A quantitative exploratory evaluation of the circle of security-parenting program with mothers in residential substance-abuse treatment. Infant Ment Health J 2015;36:320-36.

78. Renk K, Boris NW. Creating a Circle of Security for Substance-Involved mothers and their parenting. Poster presented at the Biannual Convention of the Society for Research in Child Development. Philadelphia, Pennsylvania, March 2015.

79. Sadler LS, Slade A, Mayes L. Minding the baby: A mentalization-based parenting program. In: Allen J, Fonagy P, eds. Handbook of MentalizationBased Treatment. Hoboken: Wiley, 2006:271-88.

80. Söderström K, Skårderud F. Minding the baby. Mentalization-based treatment in families with parental substance use disorder: Theoretical framework. Nordic Psychol 2009;61:47-65.

81. Natale R, Scott SH, Camejo ST, Hernandez M, Sellas-Lamberty O. Cherish the family: A program model of strengths and attachment in reunifying substance-abusing mothers with their children. Child Welfare 2012;91:73-95. 